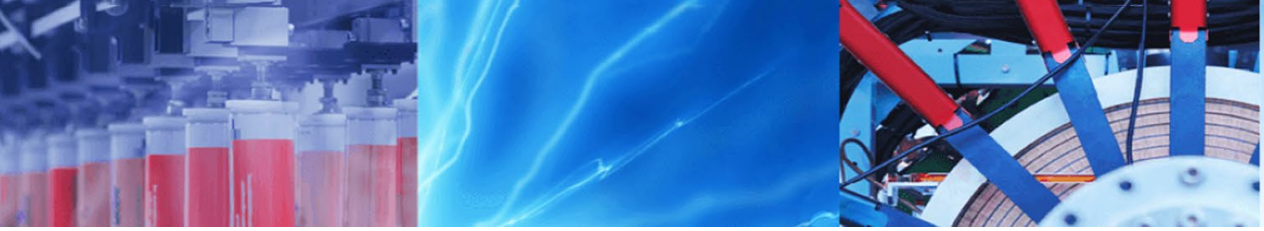

Research Article

\title{
Reliability-based optimization of geotechnical design using a constrained optimization technique
}

\author{
Zafar Mahmood $^{1}$
}

Received: 26 August 2019 / Accepted: 3 January 2020 / Published online: 8 January 2020

(c) Springer Nature Switzerland AG 2020

\begin{abstract}
Uncertainty and risk are inherent in geotechnical engineering. Reliability-based optimization (RBO) is a methodology that determines the best design solution according to certain design criteria while explicitly considering the effects of uncertainty. RBO ensures a design that is economical as well as reliable in the presence of uncertainties. This paper suggests a direct method for RBO of geotechnical systems by coupling reliability assessment and cost minimization. RBO is proposed as a double-loop (or nested-loop) constrained optimization problem, with cost optimization of geotechnical system through the outer loop repeatedly calling the inner reliability evaluation loop. First-order reliability method is used to compute the reliability index. An algorithm based on constrained optimization is proposed. MATLAB's constrained optimization function, fmincon, is used in two loops: the outer loop to minimize the cost of geotechnical system, and the inner loop to minimize the reliability index to a target value while satisfying geotechnical design requirements. The proposed method is employed to obtain the optimal design of a gravity retaining wall, and compared with other methods, and found to be robust, accurate and feasible.
\end{abstract}

Keywords Reliability-based optimization · Reliability analysis · Constrained optimization · First-order reliability method . Retaining wall

\section{Introduction}

It is well known that uncertainty and risk are inherent in geotechnical and geological engineering and that the quantification of these uncertainties is rational [1-7]. Traditional deterministic design methods accommodate uncertainties through empirical safety factors. However, these safety factors do not quantitatively measure the safety margin of design and do not account for the influence of different design variables and their uncertainties on overall system performance.

Reliability is the probability of an event occurring or the probability of a positive outcome and can be interpreted as a probability of failure. Calculating reliability gives a means of assessing the degree of uncertainty involved in geotechnical engineering calculations [6].

From the reliability theory, the chance of unsatisfactory performance can be expressed as $P_{f}=1-\Phi(\beta)$ where $P_{f}$ is failure probability, $\beta$ is the reliability index, and $\Phi$ is cumulative distribution function (CDF) of a standard normal variable. Phoon and Ching [6] define the reliability index, $\beta$, as the number of standard deviations between the most likely value of factor of safety and the critical factor of safety of 1.0. By setting target the reliability index, the chance of unsatisfactory performance can be reduced. For geotechnical systems, the target reliability index is often in the range of 2.0-4.0 [8].

Reliability-based optimization (RBO) is a methodology that determines the best design solution according

Zafar Mahmood, zafar.m@uob.edu.om | 'Department of Civil and Architectural Engineering, College of Engineering, University of Buraimi, P.O. Box 890, 512 Al-Buraimi, Sultanate of Oman. 
to certain predefined design criteria while explicitly considering the effects of uncertainty [9]. Uncertainties in geotechnical engineering come from loads, geotechnical properties and calculation models [10,11]. RBO constitutes a powerful methodology for solving geotechnicalrelated design problems because it results in a geotechnical solution optimized according to predefined criteria (e.g. construction costs, benefits, etc.) while accounting for unavoidable uncertainties and satisfying geotechnical design requirements.

RBO is emerging as a design based on safety-underuncertainty. A number of studies have been carried out for the Reliability-Based Optimization of geotechnical systems in recent past. Valdebenito and Schuëller [9] carried a detailed literature review on reliability-based optimization. Wang and Kulhawy [12] and Wang [13] used partial factors derived from reliability theory to optimize the design of shallow foundations. The partial factors needed calibration for their method. The inverse reliability approach has been used to demonstrate the optimum design of cantilever sheet pile walls [14] and anchored sheet pile walls [15]. Ching and $\mathrm{Hsu}$ [16] proposed a methodology to transform reliability limit-state constraints into deterministic limitstate constraints. Ching [17] presented an equivalence between reliability and factor of safety. Zhang et al. [8] presented an indirect method on the basis of the Mean FirstOrder Reliability Method (MFORM) to optimize the geotechnical system. Langford and Diederchs [18] developed a reliability-based design of a composite tunnel lining by combining a modified Rosenbluth Point Estimate Method (PEM), First Order Reliability Method (FORM), Monte Carlo Sampling method, and finite element analysis. Gong et al. [19] proposed and applied a fuzzy set-based Robust Geotechnical Design (RGD) method for the design of shielddriven tunnels. Zhao et al. [20] employed an Artificial Bee Colony $(A B C)$ algorithm for reliability-based optimization retaining walls and spread footings. Zevgolis et al. [21] proposed a probabilistic geotechnical design optimization framework for large open pit excavations. Zhao et al. [22] employed least square support vector machine (LSSVM) and artificial bee colony (ABC) algorithm for reliabilitybased support optimization of rockbolt reinforcement around tunnels. Santos et al. [23] used FORM based ant colony optimization (ACO) algorithm for reliability-based design optimization of geosynthetic-reinforced soil walls. Ji et al. [24] used inverse FORM approach for reliabilitybased design in geotechnical engineering. Raviteja and Basha [25] presented a target reliability-based design optimization (TRBDO) approach of V-shaped anchor trenches for municipal solid waste (MSW) landfills.

Although considerable research work has been reported in the field of RBO of geotechnical systems, the application is still limited. One limitation has been the difficulty of direct coupling between reliability assessment and cost minimization. This paper suggests a FORM-based direct method for RBO of geotechnical systems. In the proposed method, RBO is implemented by coupling reliability assessment and cost minimization. RBO is proposed as a double-loop (or nested-loop) constrained optimization problem, with cost optimization of the geotechnical system through the outer loop repeatedly calling the inner reliability evaluation loop. In the outer loop, the objective is the minimization of cost function while the constraint is a target reliability index; whereas, in the inner loop, the objective is the minimization of reliability index while constraints are geotechnical design requirements. The proposed method is used to illustrate the optimal design of retaining wall. MATLAB's constraint optimization function, fmincon [26], is used to implement this algorithm. The interior-point algorithm is used in the outer loop to search the design variables in global search space. The interior-point algorithm is used in the inner loop to calculate the reliability index.

\section{Hasofer-Lind index and FORM algorithm}

The stability of an engineering system, owing to the inherent uncertainty of input variables, is measured by the reliability index. The Hasofer-Lind index is widely used as a reliability index [27], the matrix formulation of which is,

$\beta=\min _{x \in F} \sqrt{(X-\mu)^{T} C^{-1}(X-\mu)}$

where $X$ is a vector that represents a set of random variables $X_{i}, \mu$ is a vector of mean values, $C$ is the covariance matrix, and $F$ is the failure domain. The superscripts " $T$ " and " -1 " denote transpose and inverse respectively. The Hasofer-Lind index can be regarded as the shortest distance in directional standard deviation units from the mean value point of the random variables to the boundary of the limit state surface.

Low and Tang [28-30] presented an alternative formulation of the Hasofer-Lind index, Eq. 1, based on the perspective of an expanding ellipsoid in the original space of the basic random variables and expressed the index as

$\beta=\min _{x \in F} \sqrt{\left[\frac{x_{i}-\mu_{i}}{\sigma_{i}}\right]^{T} R^{-1}\left[\frac{x_{i}-\mu_{i}}{\sigma_{i}}\right]}$

where $R$ is the correlation matrix, $\sigma_{i}$ is the standard deviation of random variable $x_{i}$.

For correlated non-normal parameters, Low and Tang [30] modified Eq. 2 as the following 
$\beta=\min _{x \in F} \sqrt{\left[\frac{x_{i}-\mu_{i}^{N}}{\sigma_{i}^{N}}\right]^{T} R^{-1}\left[\frac{x_{i}-\mu_{i}^{N}}{\sigma_{i}^{N}}\right]}$

where $\mu_{i}^{N}$ and $\sigma_{i}^{N}$ are the equivalent normal mean and equivalent normal standard deviation, respectively, for random variable $x_{i}$ and can be calculated by the Rackwitz and Fiessler [31] transformation. The computation of $\beta$ is regarded as that of finding the smallest equivalent hyperellipsoid (centered at the equivalent normal mean-value $\mu^{N}$ and with equivalent standard deviation $\sigma^{N}$ ) that is tangent to the limit state surface.

Low and Tang [32] presented an efficient alternative to Eq. 3 to calculate the reliability index $\beta$ by varying dimensionless number $n_{i}$ as the following equation

$\beta=\min _{x \in F} \sqrt{\mathbf{n}^{T} R^{-1} \mathbf{n}}$

where $\mathbf{n}$, termed as an equivalent standard normal vector, is a column vector of $n_{i}$. Low and Tang [32] have shown that random variable $x_{i}$ can be obtained from $n_{i}$ by Eq. $5 a$ for normal distribution and by Eq. $5 b$ for the lognormal distribution.

$x_{i}=\mu_{i}+n_{i} \sigma_{i}$

$x_{i}=\exp \left[\lambda+\zeta n_{i}\right], \quad \zeta=\sqrt{\ln \left[1+\left(\sigma_{i} / \mu_{i}\right)^{2}\right]}, \quad \lambda=\ln \mu_{i}-0.5 \zeta^{2}$

The reliability index, in this study, is calculated using Eq. 4 as proposed by Low and Tang [32].

\section{MATLAB constrained optimization function, fmincon}

The constrained minimization [26] is the technique of finding a vector $\boldsymbol{x}$ that is the local minimum to a scalar function $f(x)$ subject to constraints on the allowable $x$ :

$\min _{x} f(x)$ suchthat $\left\{\begin{array}{l}c(x) \leq 0 \\ c_{e q}(x)=0 \\ A \cdot x \leq b \\ A_{e q} \cdot x=b \\ l b \leq x \leq u b\end{array}\right.$

where $b$ and $b_{e q}$ are vectors, $A$ and $A_{e q}$ are matrices, $c(x)$ and $c_{e q}(x)$ are functions that return vectors, $l b$ and $u b$ are lower and upper bounds, respectively and $f(x)$ is a function that returns a scalar. In MATLAB's Optimization toolbox, fmincon function is used for constrained optimization. MATLAB uses different nonlinear methods including Trust Region
Reflective algorithm, Sequential Quadratic Programming (SQP) algorithm, and Interior Point algorithm.

\section{Reliability-based optimization using a constrained optimization technique}

In order to minimize the cost of a geotechnical system while satisfying a minimum value of the reliability index, termed as target reliability index $\beta_{T}$, MATLAB constrained optimization function, fmincon, is used. It is a two-level (or double loop) optimization problem. The fmincon function is used in two loops; the outer loop to minimize the cost of the geotechnical system and the inner loop to minimize the reliability index $\beta$ to a target reliability index value $\beta_{T}$ while satisfying geotechnical design requirements (Fig. 1).

Calculation sequence to minimize the cost function of the geotechnical system, referred to as an outer loop, is summarized as follows:

Step 1: Initialize design variables (e.g. dimension of the geotechnical system).

Step 2: Run the interior-point algorithm with MATLAB fmincon function. The objective is the minimization of the cost of the geotechnical system. The constraint is the target reliability index $\beta_{T}$. The calculated $\beta$ should be less than or equal to $\beta_{T}$. For the calculation of $\beta$, the control is passed to the inner loop where the $\beta$ is calculated (Eq. 4) and control is passed back.

Step 3: If the cost of the geotechnical system is minimized while satisfying the target beta constraint (i.e. $\beta-\beta_{T} \leq 0$ ), optimal design requirements are satisfied.

Step 4: If the cost of the geotechnical system is not minimum, design variables are modified and the process is repeated from step 2 .

Calculation sequence to obtain the reliability index $\beta$, referred to as the inner loop, is summarized as follows:

Step 1: Initialize vector $\mathbf{n}$.

Step 2: Run the interior-point algorithm with MATLAB fmincon function. The objective is the minimization of the reliability index $\beta$. The constraints are geotechnical design equations (e.g. factor of safety against overturning, sliding, bearing capacity, and eccentricity for a gravity retaining wall).

Step 3: Calculate $\beta$ using Eq. 4. If the $\beta$ is minimum while satisfying the geotechnical design equations, pass control to the outer loop.

Step 4: If the $\beta$ is not minimum, vector $\mathbf{n}$ is modified and the process is repeated from Step 2. 
Fig. 1 Flowchart of reliabilitybased optimization algorithm

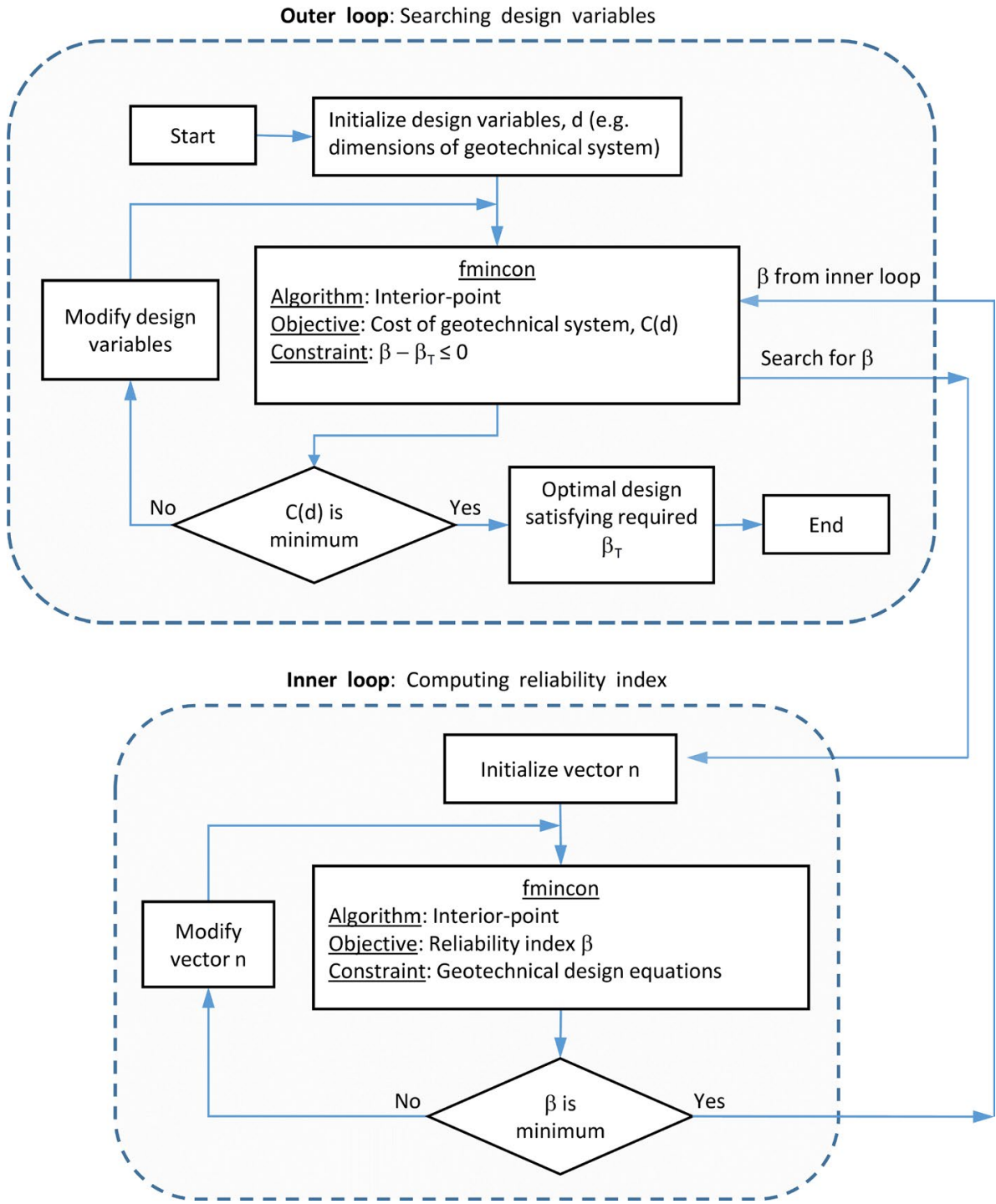

The flowchart of the above-mentioned calculation sequence is shown in Fig. 1.

\section{Illustrative example: retaining wall design}

Gravity retaining wall design is adopted to illustrate the application RBO. Four failure modes are considered: (1) overturning failure, (2) sliding failure, (3) bearing capacity failure and, (4) eccentricity failure. Each failure mode is a design constraint. The goal is to obtain a design with minimum wall area (i.e. cost function) satisfying both target reliability requirements in addition to all design requirements. Gravity retaining wall design, adopted from the literature [8,20], is based on Knappett and Craig [33]. A $6 \mathrm{~m}$ high concrete gravity retaining wall, as shown in Fig. 2 is considered.
The active force $F_{a}$, based on Coulomb's earth pressure theory [33] is given as

$F_{a}=0.5 K_{a} \gamma_{s} H^{2}$

where $K_{a}$ is coulomb's active earth pressure coefficient. Based on Fig. 2, the following geometric relationships exist:

$\theta=a \tan \left(\frac{b_{3}}{H}\right)$

$\alpha=\delta_{w}+\theta$

$B=b_{1}+b_{2}+b_{3}$

The forces and moment arms involved in the overturning limit state are listed in Table 1. 


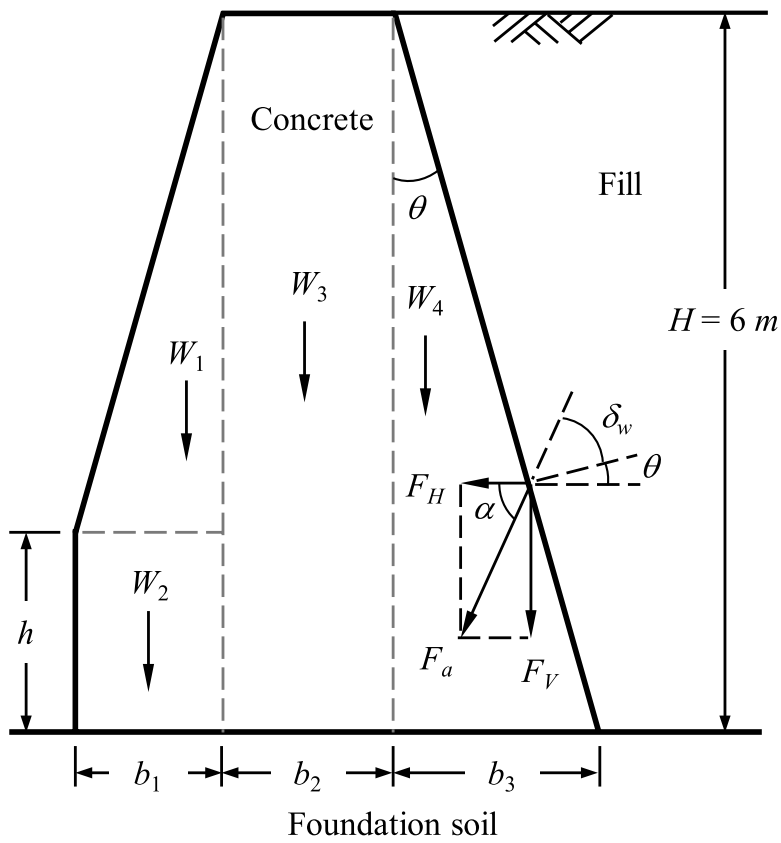

Fig. 2 Reliability-based design of gravity retaining wall (based on Zhang et al. [8])

Table 1 Forces and moment arms for rotational failure of retaining wall

\begin{tabular}{ll}
\hline Force & Moment arm \\
\hline$W_{1}=0.5 b_{1}(H-h) \gamma_{c}$ & $a_{1}=2 b_{1} / 3$ \\
$W_{2}=b_{1} h \gamma_{c}$ & $a_{2}=b_{1} / 3$ \\
$W_{3}=b_{2} h \gamma_{c}$ & $a_{3}=b_{1}+0.5 b_{2}$ \\
$W_{4}=b_{3} H \gamma_{c} / 2$ & $a_{4}=b_{1}+b_{2}+b_{3} / 3$ \\
$F_{H}=F_{a} \cos (\alpha)$ & $a_{F_{H}}=H / 3$ \\
$F_{V}=F_{a} \sin (\alpha)$ & $a_{F_{V}}=b_{1}+b_{2}+2 b_{3} / 3$ \\
\hline
\end{tabular}

\subsection{Limit state function for overturning failure}

Based on the forces and moment arms shown in Table 1, the resisting moment $M_{R}$ and overturning moment $M_{O}$ are given in the following equations:

$M_{R}=\sum_{i=1}^{4} W_{i} a_{i}+F_{V} a_{F_{V}}$

$M_{O}=F_{H} a_{F_{H}}$

The limit state function for overturning failure is

$g_{1}(\mathbf{x})=M_{R}-M_{O}$

\subsection{Limit state function for sliding failure}

Considering the force equilibrium in the vertical direction, the resultant base reaction $R_{V}$ is

$R_{V}=\sum_{i=1}^{4} W_{i}+F_{V}$

The limit state function for sliding failure is

$g_{2}(\mathbf{x})=R_{V} \tan \left(\delta_{b}\right)+B c_{b}-F_{H}$

\subsection{Limit state functions of bearing capacity and eccentricity failure}

Considering the moment equilibrium at the toe, the moment arm of the resultant base reaction is given by

$a_{R_{V}}=\left(M_{R}-M_{O}\right) / R_{V}$

The eccentricity of base reaction is given by

$e=0.5 B-a_{R_{V}}$

The maximum base pressure is given by

$q_{\max }=\frac{R_{V}}{B}\left(1+\frac{6 e}{B}\right)$

The limit state functions for bearing capacity and eccentricity are given by Eqs. 19 and 20 respectively.

$g_{3}(\mathbf{x})=q_{u}-\frac{R_{V}}{B}\left(1+\frac{6 e}{B}\right)$

$g_{4}(\mathbf{x})=1-\frac{6 e}{B}$

Limit state functions for overturning (Eq. 13), sliding (Eq. 15), bearing capacity (Eq. 19), and eccentricity (Eq. 20) are the geotechnical design requirements.

\subsection{Uncertainties of input variables}

Six uncertain variables are considered: the friction angle of backfill material $\left(\phi_{f}\right)$; the friction angle between the backfill material and the retaining wall $\left(\delta_{w}\right)$; the unit weight of backfill material $\left(\gamma_{f}\right)$; the cohesion along the interface between the wall base and the founding soil $\left(c_{b}\right)$; the friction angle along the interface between the wall base and the founding soil $\left(\delta_{b}\right)$, and the maximum allowable bearing pressure of the foundation $\left(q_{u}\right)$. The distribution and statistics of these variables are adopted from [8] and summarized in Table 2 . The correlation matrix assumed for 
Table 2 Distribution and statistics of uncertain variables for retaining wall design

\begin{tabular}{lllr}
\hline Variable & Distribution & Mean & SD \\
\hline$\gamma_{f}\left(\mathrm{kN} / \mathrm{m}^{3}\right)$ & Normal & 18.5 & 1 \\
$c_{b}\left(\mathrm{kN} / \mathrm{m}^{2}\right)$ & Lognormal & 20 & 5 \\
$\delta_{b}\left({ }^{\circ}\right)$ & Lognormal & 26 & 3 \\
$q_{u}\left(\mathrm{kN} / \mathrm{m}^{2}\right)$ & Lognormal & 350 & 70 \\
$\delta_{w}\left({ }^{\circ}\right)$ & Lognormal & 24 & 3 \\
$\phi_{f}\left({ }^{\circ}\right)$ & Lognormal & 34 & 4 \\
\hline
\end{tabular}

these variables is also adopted from [8] and summarized in Table 3.

\subsection{Procedure for design optimization}

Suppose the objective is to minimize the area of a retaining wall (i.e. the cost function) by changing the design variables $\mathbf{d}=\left\{b_{1}, b_{2}, b_{3}, h\right\}$. The target failure probability for retaining wall is in the range of $0.01-0.0001[34,35]$. In this example, the target reliability index $\beta_{T} \geq 3.0$ is set for all failure modes which corresponds to the failure probability of 0.0013 . The design space is considered as $0<b_{1}<3 \mathrm{~m}$; $0.5 \mathrm{~m}<b_{2}<3 \mathrm{~m}, 0<b_{3}<3 \mathrm{~m}, 0.4 \mathrm{~m}<h<6 \mathrm{~m}$. The reliabilitybased optimization problem can be written as

$\min C(\mathbf{d})=b_{1} h+0.5(H-h) b_{1}+b_{2} H+0.5 b_{3} H$

subject to $\quad \beta_{i}(\mathbf{d}) \geq 3 \quad i=1,2,3,4$

$0<b_{1}<3$

$0.5<b_{2}<3$

$0<b_{3}<3$

$0.5<h<6$

where $C(\mathbf{d})$ is area of retaining wall and $\beta_{1}, \beta_{2}, \beta_{3}, \beta_{4}$ and are the reliability constraints for the limit states of overturning, sliding, bearing capacity and eccentricity respectively.

MATLAB's constrained optimization function, fmincon, is used for the double loop optimization problem. In the outer loop, the objective is the minimization of the area of the retaining wall (Eq. 21) while the constraint is $\beta_{i} \leq \beta_{T}$. In the inner loop, the objective is the minimization of the reliability index $\beta_{i}$ (Eq. 4) while the constraints are corresponding limit state functions of overturning failure (Eq. 13), sliding failure (Eq. 15), bearing capacity failure (Eq. 19) and eccentricity (Eq. 20) respectively.

\subsection{Results and discussion}

The optimization process is started with initial design values as $b_{1}=1.6 \mathrm{~m}, b_{2}=1 \mathrm{~m}, b_{3}=0.6 \mathrm{~m}$, and $h=1 \mathrm{~m}$. The proposed method presented in Sect. 4 is implemented in MATLAB R2018a on a laptop equipped with an Intel Core i7-7500 CPU running at $2.70 \mathrm{GHz}$. The average computational time is less than $31 \mathrm{~s}$. After running the optimization, the results summary is shown in Fig. 3 and Table 4. Four optimal scenarios listed in Table 4 are discussed below.

Overturning failure: Optimal 1 is the optimized solution when the design constraint is limit state function of overturning failure (Eq. 13) with the reliability constraint $\beta_{1}$ minimized to the target reliability index value $\beta_{T}$. Figure $4 \mathrm{a}$ shows the convergence of cost function and reliability constraint $\beta_{1}$. From the calculated values of design variables (i.e. retaining wall dimensions), reliability constraints $\beta_{2}, \beta_{3}$ and $\beta_{4}$ corresponding to limit state functions of sliding failure, bearing capacity failure and eccentricity,

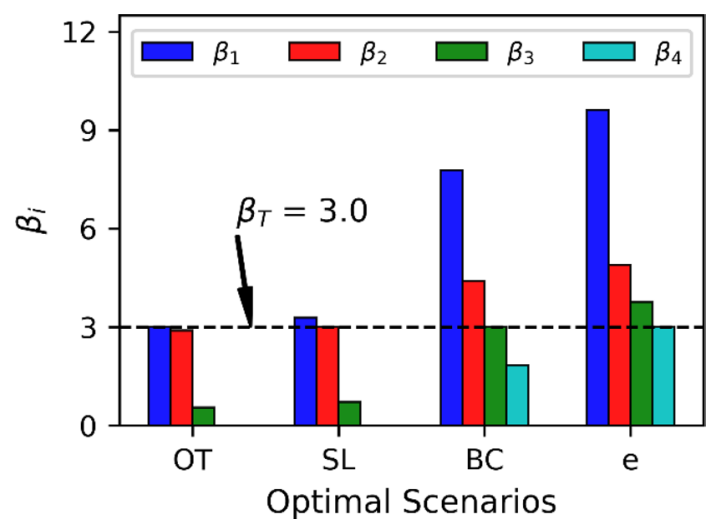

Fig. 3 Calculated values of reliability constraints $\beta_{i}$ for optimal scenarios of overturning (OT), sliding (SL), bearing capacity $(\mathrm{BC})$ and eccentricity (e) failures, respectively, for the target reliability constraint $\beta_{\mathrm{T}} \geq 3.0$
Table 3 Correlation matrix of uncertain variables for retaining wall design

\begin{tabular}{lllllll}
\hline & $\gamma_{f}$ & $c_{b}$ & $\delta_{b}$ & $q_{u}$ & $\delta_{w}$ & $\phi_{f}$ \\
\hline$\gamma_{f}$ & 1 & 0 & 0 & 0 & 0 & 0 \\
$c_{b}$ & 0 & 1 & -0.4 & 0.4 & 0 & 0 \\
$\delta_{b}$ & 0 & -0.4 & 1 & 0.4 & 0 & 0 \\
$q_{u}$ & 0 & 0.4 & 0.4 & 1 & 0 & 0 \\
$\delta_{w}$ & 0 & 0 & 0 & 0 & 1 & 0.8 \\
$\phi_{f}$ & 0 & 0 & 0 & 0 & 0.8 & 1 \\
\hline
\end{tabular}


respectively are then calculated. Figure $4 \mathrm{~b}$ shows the convergence of these reliability constraints when these are determined using Eq. 4. It is noted that only $\beta_{1}$ corresponding to overturning failure is equal to $\beta_{\mathrm{T}}$ whereas the rest of reliability constraints are less than $\beta_{\mathrm{T}}$. Thus optimal 1 does not satisfy all reliability constrains, and thus design requirements.

Sliding failure: Optimal 2 is the optimized solution when the design constraint is limit state function of sliding failure (Eq. 15) with the reliability constraint $\beta_{2}$ minimized to the target reliability $\beta_{T}$. The convergence of cost function and reliability constraint $\beta_{2}$ is shown in Fig. 5a. The rest of reliability constraints $\beta_{1}, \beta_{3}$ and $\beta_{4}$ are calculated from the optimized solution. The convergence of $\beta_{1}, \beta_{3}$ and $\beta_{4}$ are shown in Fig. 5b. Only $\beta_{1}$ and $\beta_{2}$ are above $\beta_{T}$. Thus Optimal 2 does not satisfy bearing capacity and eccentricity requirements.

Bearing capacity failure: Optimal 3 is the optimized solution when the design constraint is limit state function of bearing capacity failure (Eq. 19) with the reliability

Table 4 Optimization results for target reliability constraint $\beta_{T} \geq 3.0$

\begin{tabular}{|c|c|c|c|c|c|c|c|c|c|c|c|}
\hline \multirow[t]{2}{*}{ Optimal scenarios } & \multirow[t]{2}{*}{ Design Constraint } & \multicolumn{5}{|l|}{$d$} & \multicolumn{4}{|c|}{ Reliability constraint } & \multirow[t]{2}{*}{ Remarks } \\
\hline & & $b_{1}(\mathrm{~m})$ & $b_{2}(\mathrm{~m})$ & $b_{3}(\mathrm{~m})$ & $h(\mathrm{~m})$ & $C(d)\left(m^{2}\right)$ & $\beta_{1}^{\mathrm{a}}$ & $\beta_{2}^{\mathrm{b}}$ & $\beta_{3}^{c}$ & $\beta_{4}^{\mathrm{d}}$ & \\
\hline Optimal 1 & Overturning & 1.224 & 0.5 & 0 & 0.4 & 6.917 & 3.000 & 2.900 & 0.548 & 0.000 & All $\beta_{\mathrm{i}} \ngtr \beta_{\mathrm{T}}$ \\
\hline Optimal 2 & Sliding & 1.262 & 0.5 & 0 & 0.4 & 7.038 & 3.287 & 3.000 & 0.718 & 0.000 & All $\beta_{\mathrm{i}} \ngtr \beta_{\mathrm{T}}$ \\
\hline Optimal 3 & Bearing Capacity & 1.838 & 0.5 & 0 & 0.4 & 8.883 & 7.772 & 4.400 & 3.000 & 1.828 & All $\beta_{\mathrm{i}} \ngtr \beta_{\mathrm{T}}$ \\
\hline Optimal 4 & Eccentricity & 2.065 & 0.5 & 0 & 0.4 & 9.607 & 9.615 & 4.895 & 3.767 & 3.000 & All $\beta_{\mathrm{i}} \geq \beta_{\mathrm{T}}$ \\
\hline
\end{tabular}

${ }^{\mathrm{a}} \beta_{1}$ is the calculated value of reliability index for overturning limit state (Eq. 13)

${ }^{\mathrm{b}} \beta_{2}$ is the calculated value of reliability index for sliding limit state (Eq. 15)

${ }^{c} \beta_{3}$ is the calculated value of reliability index for bearing capacity limit state (Eq. 19)

${ }^{\mathrm{d}} \beta_{4}$ is the calculated value of reliability index for eccentricity limit state (Eq. 20)

Fig. 4 a Convergence of objective and reliability constraint $\beta_{1}$ for overturning failure, $\mathbf{b}$ determination of other reliability constraints from the optimized solution

Fig. 5 a Convergence of objective and reliability constraint $\beta_{2}$ for sliding failure, $\mathbf{b}$ determination of other reliability constraints from the optimized solution
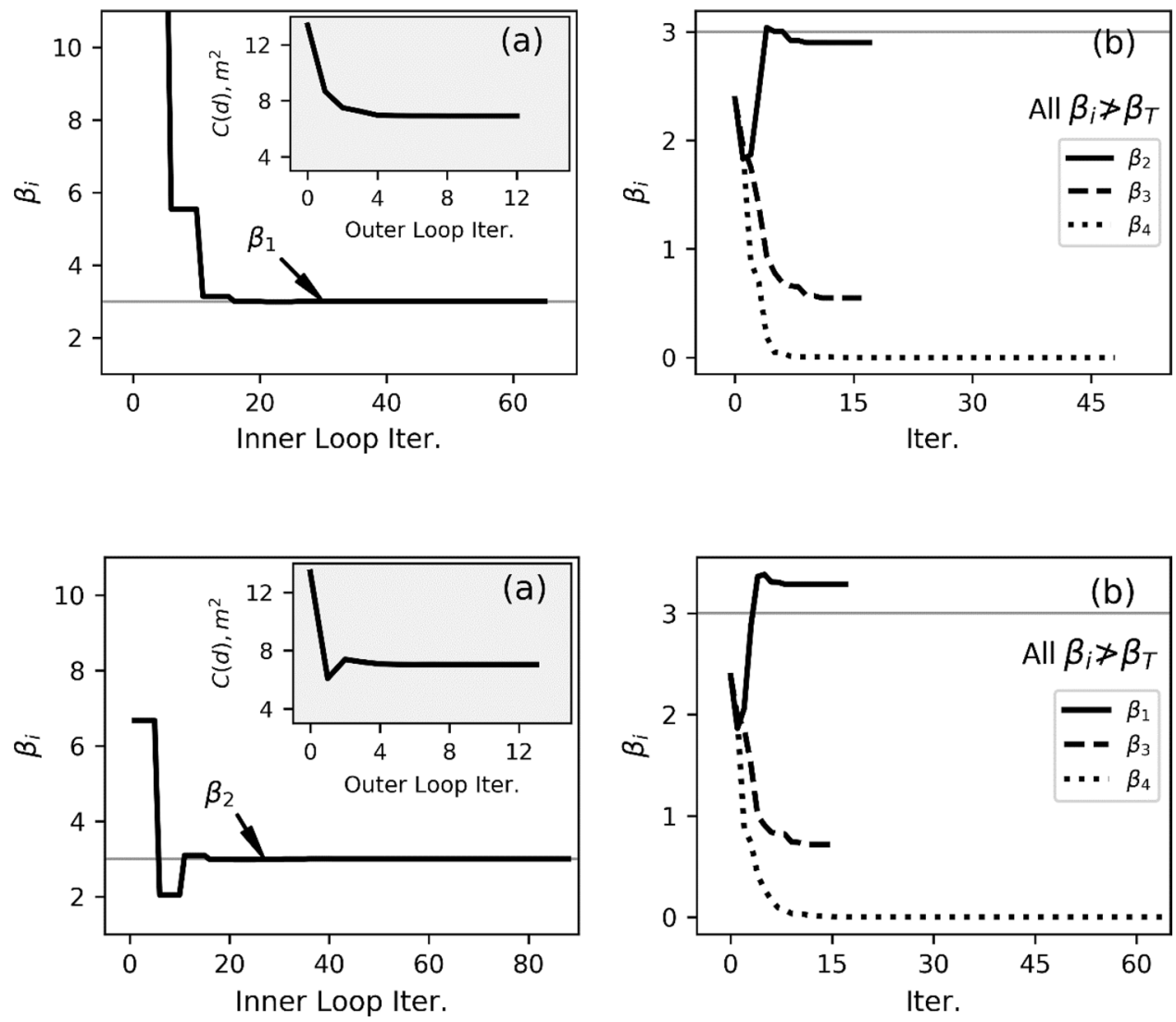

SN Applied Sciences 
Fig. 6 a Convergence of objective and reliability constraint $\beta_{3}$ for bearing capacity failure, b determination of other reliability constraints from the optimized solution
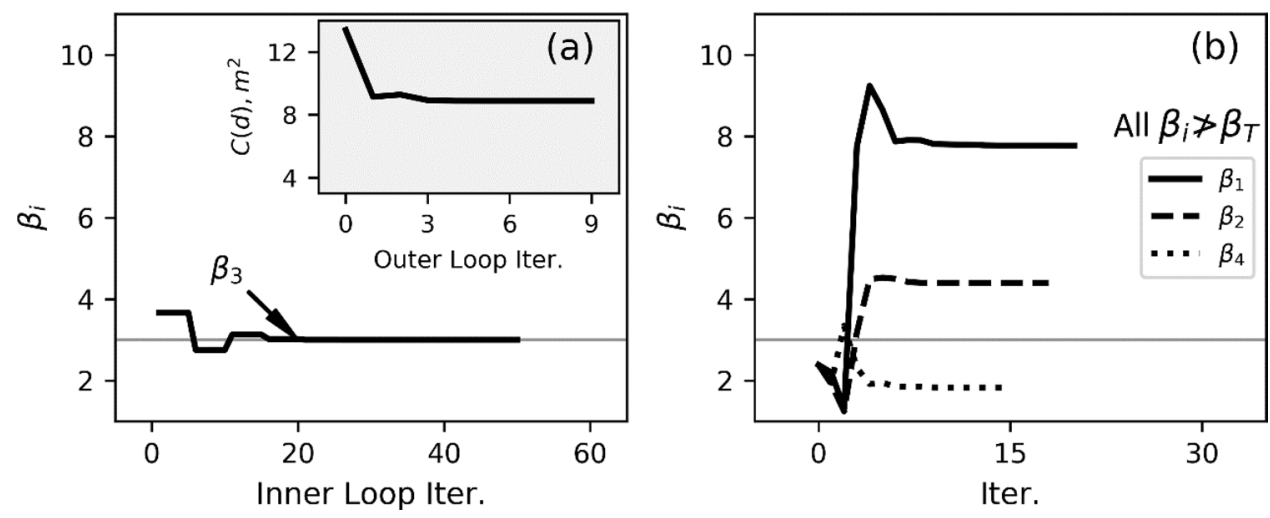

Fig. 7 a Convergence of objective and reliability constraint $\beta_{4}$ for eccentricity failure, $\mathbf{b}$ determination of other reliability constraints from the optimized solution

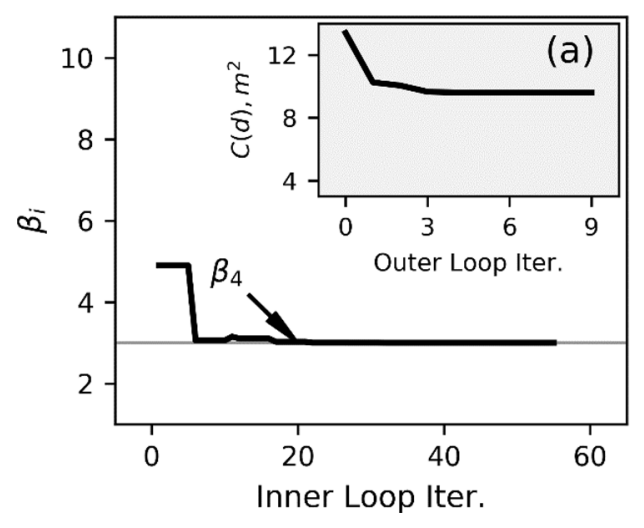

constraint $\beta_{3}$ minimized to the target reliability $\beta_{T}$. Figure $6 \mathrm{a}$ shows the convergence of cost function and reliability constraint $\beta_{3}$. The rest of reliability constraints $\beta_{1}$, $\beta_{2}$ and $\beta_{4}$ are calculated from the optimized solution as shown in Fig. 6b. Only $\beta_{4}$ is below $\beta_{T}$. Thus optimal 3 does not satisfy eccentricity requirement.

Eccentricity failure: Optimal 4 is the optimized solution when the design constraint is limit state function of eccentricity failure (Eq. 20) with the reliability constraint $\beta_{4}$ minimized to the target reliability $\beta_{\mathrm{T}}$. Figure 7a shows the convergence of cost function and reliability constraint $\beta_{4}$. Other reliability constraints $\beta_{1}, \beta_{2}$ and $\beta_{3}$ are calculated from the optimized solution as shown in Fig. 7b. All reliability constraints are above $\beta_{\mathrm{T}}$.

As seen in Fig. 3 and Table 4, only optimal 4 case satisfies all the reliability constraint requirements (i.e. All $\beta_{i} \geq \beta_{T}$ ). Thus optimal 4 is the optimized solution satisfying the reliability requirement as well as the design requirements. The Convergence of design variables (i.e. retaining wall dimensions) for the optimized solution are shown in Fig. 8. The calculated values of the reliability constraints for initial and optimized design are summarized in Table 5 . To check the accuracy of proposed method, the reliability constraints for the optimized solution are also calculated by Microsoft Excel's built-in optimization routine SOLVER

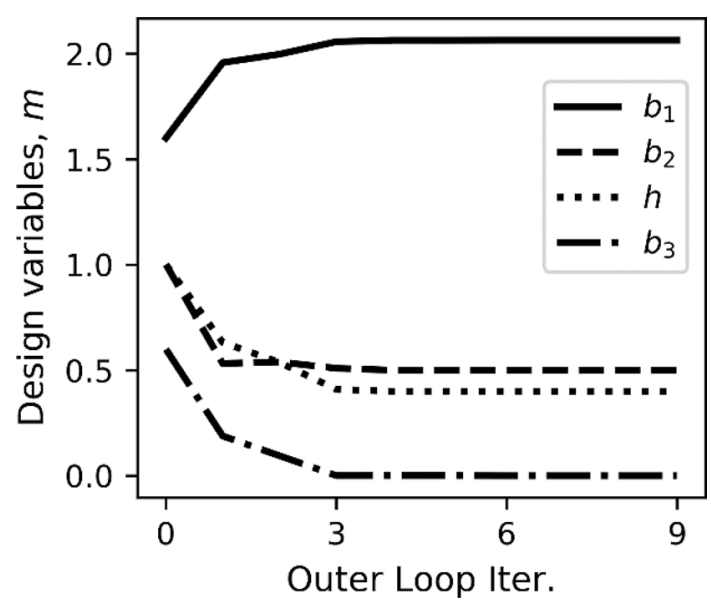

Fig. 8 Convergence of design variables for optimal 4 scenario

as proposed by Low and Tang [32]. GRG nonlinear solving method is used in Excel's optimization routine. Figure 9 shows the Excel's spreadsheet results. The reliability constraints calculated by Excel's optimization retinue match with the present study results. Equivalent standard normal vectors, $\mathbf{n}$, for all optimal scenarios are summarized in Table 6. 
Table 5 Summary of optimization results for target reliability constraint $\beta_{\mathrm{T}} \geq 3.0$

\begin{tabular}{|c|c|c|c|c|c|c|c|c|c|}
\hline & \multicolumn{5}{|l|}{$d$} & \multicolumn{4}{|c|}{ Reliability constraint } \\
\hline & $b_{1}(\mathrm{~m})$ & $b_{2}(\mathrm{~m})$ & $b_{3}(\mathrm{~m})$ & $h(\mathrm{~m})$ & $C(d)\left(\mathrm{m}^{2}\right)$ & $\beta_{1}^{\mathrm{a}}$ & $\beta_{2}^{b}$ & $\beta_{3}^{c}$ & $\beta_{4}^{\mathrm{d}}$ \\
\hline Initial & 1.6 & 1 & 0.6 & 1 & 13.400 & 17.085 & 6.667 & 3.666 & 4.897 \\
\hline Optimized & 2.065 & 0.5 & 0 & 0.4 & 9.607 & 9.615 & 4.895 & 3.767 & 3.000 \\
\hline
\end{tabular}

${ }^{\mathrm{a}} \beta_{1}$ is the calculated value of reliability index for overturning limit state (Eq. 13)

${ }^{\mathrm{b}} \beta_{2}$ is the calculated value of reliability index for sliding limit state (Eq. 15)

${ }^{c} \beta_{3}$ is the calculated value of reliability index for bearing capacity limit state (Eq. 19)

${ }^{\mathrm{d}} \beta_{4}$ is the calculated value of reliability index for eccentricity limit state (Eq. 20)

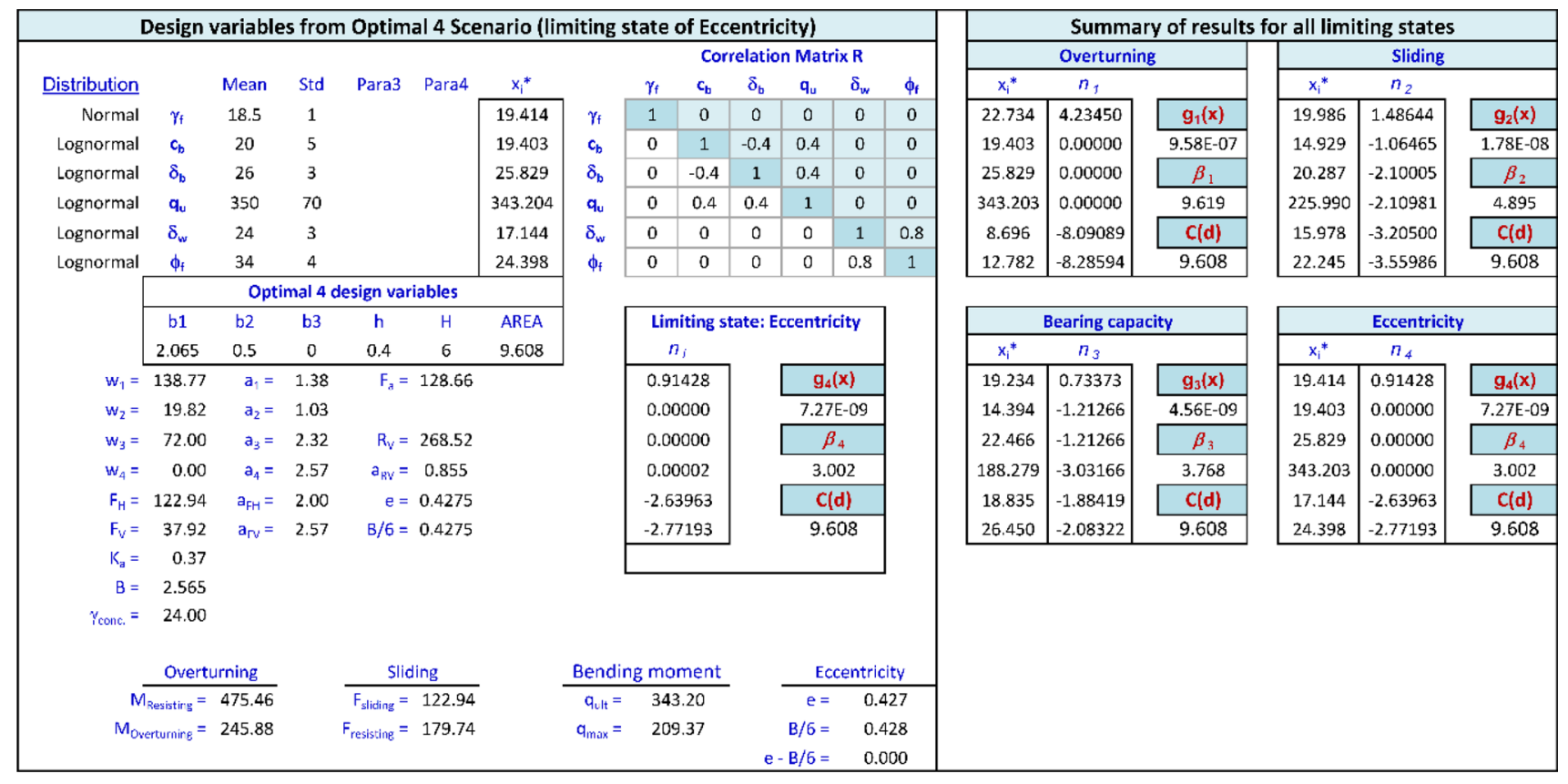

Fig. 9 Verification of Optimal 4 calculations for $\beta_{i}$ using EXCEL's solver

Table 6 Equivalent standard normal vector $\mathbf{n}$ for different optimal scenarios

\begin{tabular}{|c|c|c|c|c|c|c|c|c|}
\hline & $\beta_{1}$ & $\beta_{2}$ & $\beta_{3}$ & $\beta_{4}$ & $\beta_{1}$ & $\beta_{2}$ & $\beta_{3}$ & $\beta_{4}$ \\
\hline & \multicolumn{4}{|c|}{ Optimal 1 design variables } & \multicolumn{4}{|c|}{ Optimal 2 design variables } \\
\hline$n_{1}$ & 0.91091 & 0.80230 & 0.10365 & 0.00000 & 1.01921 & 0.83484 & 0.13638 & 0.00000 \\
\hline$n_{2}$ & 0.00000 & -0.47681 & -0.16355 & 0.00000 & 0.00000 & -0.50318 & -0.21561 & 0.00000 \\
\hline$n_{3}$ & 0.00000 & -1.23312 & -0.16355 & 0.00000 & 0.00000 & -1.27563 & -0.21561 & 0.00000 \\
\hline$n_{4}$ & 0.00000 & -1.13995 & -0.40887 & 0.00000 & 0.00000 & -1.18587 & -0.53904 & 0.00000 \\
\hline$n_{5}$ & -2.63928 & -2.01413 & -0.30568 & 0.00000 & -2.88881 & -2.07790 & -0.39820 & 0.00000 \\
\hline$n_{6}$ & -2.76933 & -2.23058 & -0.34574 & 0.00000 & -3.02650 & -2.30158 & -0.44984 & 0.00000 \\
\hline & \multicolumn{4}{|c|}{ Optimal 3 design variables } & \multicolumn{4}{|c|}{ Optimal 4 design variables } \\
\hline$n_{1}$ & 3.14289 & 1.30996 & 0.58348 & 0.50770 & 4.23191 & 1.48605 & 0.73341 & 0.91332 \\
\hline$n_{2}$ & 0.00000 & -0.90828 & -0.95204 & 0.00000 & 0.00000 & -1.06431 & -1.21211 & 0.00000 \\
\hline$n_{3}$ & 0.00000 & -1.87936 & -0.95204 & 0.00000 & 0.00000 & -2.09957 & -1.21211 & 0.00000 \\
\hline$n_{4}$ & 0.00000 & -1.85842 & -2.38010 & 0.00000 & 0.00000 & -2.10925 & -3.03027 & 0.00000 \\
\hline$n_{5}$ & -6.63972 & -2.92364 & -1.53572 & -1.61369 & -8.08771 & -3.20440 & -1.88346 & -2.63737 \\
\hline$n_{6}$ & -6.83396 & -3.24513 & -1.70728 & -1.70608 & -8.28277 & -3.55921 & -2.08244 & -2.76959 \\
\hline
\end{tabular}


Table 7 Comparison with past studies

\begin{tabular}{|c|c|c|c|c|c|c|c|c|c|c|}
\hline \multirow[t]{2}{*}{ Ref. } & \multirow[t]{2}{*}{ Method } & \multicolumn{5}{|l|}{$d$} & \multicolumn{4}{|c|}{ Reliability Constraint } \\
\hline & & $b_{1}(\mathrm{~m})$ & $b_{2}(\mathrm{~m})$ & $b_{3}(\mathrm{~m})$ & $h(\mathrm{~m})$ & $C(d)\left(m^{2}\right)$ & $\beta_{1}$ & $\beta_{2}$ & $\beta_{3}$ & $\beta_{4}$ \\
\hline Zhang et al. [8] & $\begin{array}{l}\text { Indirect RBO using modified FORM } \\
\text { and a mapping function }\end{array}$ & 2.086 & 0.5 & 0 & 0.4 & 9.675 & 9.390 & 4.849 & 3.849 & 2.996 \\
\hline Zhao et al. [20] & $\mathrm{ABC}$ algorithm and excel solver & 2.065 & 0.5 & 0 & 0.4 & 9.607 & 9.616 & 4.893 & 3.768 & 3.005 \\
\hline Present study & MATLAB constrained optimization & 2.065 & 0.5 & 0 & 0.4 & 9.607 & 9.615 & 4.895 & 3.767 & 3.000 \\
\hline
\end{tabular}

The results obtained from the present study are compared, in Table 7, with past studies $[8,20]$. The results of the present study match precisely with those reported by Zhao et al. [20]. Zhao et al. [20] used Artificial Bee Colony $(A B C)$ algorithm and Microsoft Excel's SOLVER. Zhang et al. [8] used an indirect method by using a mapping function. The advantage of the proposed method, over others $[8,20]$, is its direct approach which couples reliability assessment and cost minimization. This study shows that MATLAB's constrained optimization technique can be used in double-loop optimization problems encountered in geotechnical engineering.

\section{Conclusions}

The findings of the study reported in this paper are summarized as follows:

1. A direct method is proposed for reliability-based optimization (RBO) by coupling reliability assessment and cost optimization. RBO is proposed as a double-loop (or nested-loop) constrained optimization problem, with cost optimization of the geotechnical system through the outer loop repeatedly calling the inner reliability evaluation loop.

2. MATLAB's constrained optimization function, fmincon, is used to implement the algorithm. The interior-point algorithm is used in both loops.

3. The optimal design of gravity retaining wall is illustrated using the proposed method. The results of the optimal design match precisely with those reported earlier $[8,20]$. The reliability constraints of the optimized solution are verified by calculating them using Microsoft Excel's SOLVER.

4. The advantage of the proposed method is its direct approach which couples reliability assessment and cost minimization.

\section{Compliance with ethical standards}

Conflict of interest The authors declare that they have no conflict of interest.

\section{References}

1. Casagrande A (1965) Role of the calculated risk in earthwork and foundation engineering. J Soil Mech Found Div ASCE 91:1-40

2. Whitman RV (2000) Organizing and evaluating uncertainty in geotechnical engineering. J Geotech Geoenviron Eng ASCE 126:583-593. https://doi.org/10.1061/ (ASCE) 1090-0241(2000)126:7(583)

3. Phoon K-K, Kulhawy FH (1999) Evaluation of geotechnical property variability. Can Geotech J 36:625-639. https://doi. org/10.1139/t99-039

4. Phoon K-K, Kulhawy FH (1999) Characterization of geotechnical variability. Can Geotech J 36:612-624. https://doi. org/10.1139/t99-038

5. Phoon K-K (2008) Reliability-based design in geotechnical engineering: computations and applications. Taylor \& Francis, London

6. Phoon K-K, Ching J (2015) Risk and reliability in geotechnical engineering. CRC Press, Boca Raton

7. Christian JT (2004) Geotechnical engineering reliability: How well do we know what we are doing? J Geotech Geoenviron Eng 130:985-1003. https://doi.org/10.1061/ (ASCE) 1090-0241(2004)130:10(985)

8. Zhang J, Zhang LM, Tang WH (2011) Reliability-based optimization of geotechnical systems. J Geotech Geoenviron Eng 137:1211-1221. https://doi.org/10.1061/(ASCE)GT.19435606.0000551

9. Valdebenito MA, Schuëller GI (2010) A survey on approaches for reliability-based optimization. Struct Multidiscip Optim 42:645-663. https://doi.org/10.1007/s00158-010-0518-6

10. Baecher GB, Christian JT (2003) Reliability and statistics in geotechnical engineering. Wiley, $\mathrm{NJ}$

11. Ang AH-S, Tang WH (2007) Probability concepts in engineering: emphasis on applications in civil environmental engineering, 2nd edn. Wiley, New York

12. Wang Y, Kulhawy FH (2008) Economic design optimization of foundations. J Geotech Geoenviron Eng 134:1097-1105

13. Wang $Y(2009)$ Reliability-based economic design optimization of spread foundations. J Geotech Geoenviron Eng ASCE 135:954-959. https://doi.org/10.1061/(ASCE)GT.19435606.0000013

14. Babu GLS, Basha BM (2008) Optimum design of cantilever sheet pile walls in sandy soils using inverse 
reliability approach. Comput Geotech 35:134-143. https:// doi.org/10.1016/J.COMPGEO.2007.04.001

15. Basha BM, Babu GLS (2008) Target reliability based design optimization of anchored cantilever sheet pile walls. Can Geotech J 45:535-548. https://doi.org/10.1139/T08-004

16. Ching J, Hsu W-C (2008) Transforming reliability limit-state constraints into deterministic limit-state constraints. Struct Saf 30:11-33. https://doi.org/10.1016/J.STRUSAFE.2006.04.002

17. Ching J (2009) Equivalence between reliability and factor of safety. Probab Eng Mech 24:159-171. https://doi.org/10.1016/j. probengmech.2008.04.004

18. Connor Langford J, Diederichs MS (2013) Reliability based approach to tunnel lining design using a modified point estimate method. Int J Rock Mech Min Sci 60:263-276. https://doi. org/10.1016/j.ijrmms.2012.12.034

19. Gong W, Wang L, Juang CH et al (2014) Robust geotechnical design of shield-driven tunnels. Comput Geotech 56:191-201. https://doi.org/10.1016/j.compgeo.2013.12.006

20. Zhao H, Zhao M, Zhu C (2016) Reliability-based optimization of geotechnical engineering using the artificial bee colony algorithm. KSCE J Civ Eng 20:1728-1736. https://doi.org/10.1007/ s12205-015-0117-6

21. Zevgolis IE, Deliveris AV, Koukouzas NC (2018) Probabilistic design optimization and simplified geotechnical risk analysis for large open pit excavations. Comput Geotech 103:153-164. https://doi.org/10.1016/J.COMPGEO.2018.07.024

22. Zhao H, Ru Z, Zhu C (2018) Reliability-based support optimization of rockbolt reinforcement around tunnels in rock masses. Period Polytech Civ Eng 62:250-258. https://doi.org/10.3311/ PPci. 10420

23. Santos MGC, Silva JL, Beck AT (2018) Reliability-based design optimization of geosynthetic-reinforced soil walls. Geosynth Int 25:442-455. https://doi.org/10.1680/jgein.18.00028

24. Ji J, Zhang C, Gao Y, Kodikara J (2019) Reliability-based design for geotechnical engineering: an inverse FORM approach for practice. Comput Geotech 111:22-29. https://doi.org/10.1016/j. compgeo.2019.02.027
25. Raviteja KVNS, Basha BM (2018) Optimal reliability based design of V-shaped anchor trenches for MSW landfills. Geosynth Int 25:200-214. https://doi.org/10.1680/jgein.18.00002

26. MATLAB (2018) Optimization toolbox user's guide. The MathWorks Inc., Natick

27. Hasofer AM, Lind NC (1974) An exact and invariant secondmoment code format. J Eng Mech Div 100:111-121

28. Low BK, Tang WH (1997) Efficient reliability evaluation using spreadsheet. J Eng Mech 123:749-752. https://doi.org/10.1061/ (ASCE)0733-9399(1997)123:7(749)

29. Low BK, Tang WH (1997) Reliability analysis of reinforced embankments on soft ground. Can Geotech J 34:672-685. https ://doi.org/10.1139/t97-032

30. Low BK, Tang WH (2004) Reliability analysis using object-oriented constrained optimization. Struct Saf 26:69-89. https:// doi.org/10.1016/S0167-4730(03)00023-7

31. Rackwitz R, Flessler B (1978) Structural reliability under combined random load sequences. Comput Struct 9:489-494. https ://doi.org/10.1016/0045-7949(78)90046-9

32. Low BK, Tang WH (2007) Efficient spreadsheet algorithm for firstorder reliability method. J Eng Mech 133:1378-1387. https://doi. org/10.1061/(ASCE)0733-9399(2007)133:12(1378)

33. Knappett J, Craig RF (2012) Craig's soil mechanics. Spon Press, London

34. Baecher GH (1987) Geotechnical risk analysis user's guide, FHWA/RD-87-011. McLean, VA

35. Chalermyanont T, Benson CH (2004) Reliability-based design for internal stability of mechanically stabilized earth walls. J Geotech Geoenviron Eng 130:163-173. https://doi.org/10.1061/ (ASCE)1090-0241(2004)130:2(163)

Publisher's Note Springer Nature remains neutral with regard to jurisdictional claims in published maps and institutional affiliations. 